\title{
Phenome-wide examination of comorbidity burden and multiple sclerosis disease severity
}

Tingting Zhang, PhD, * Matthew Goodman, PhD,* Feng Zhu, MSc, Brian Healy, PhD, Robert Carruthers, MD, Tanuja Chitnis, MD, Howard Weiner, MD, Tianxi Cai, ScD, Philip De Jager, MD, PhD, Helen Tremlett, PhD, ** and Zongqi Xia, MD, $\mathrm{PhD} * *$

Neurol Neuroimmunol Neuroinflamm 2020;7:e864. doi:10.1212/NXI.0000000000000864

\section{Abstract}

\section{Objective}

We assessed the comorbidity burden associated with multiple sclerosis (MS) severity by performing a phenome-wide association study (PheWAS).

\section{Methods}

We conducted a PheWAS in 2 independent cohorts: a discovery (Boston, United States; 1993-2014) and extension cohort (British Columbia, Canada; 1991-2008). We included adults with MS, $\geq 1$ Expanded Disability Status Scale (EDSS) score, and $\geq 1$ International Classification of Diseases (ICD) code other than MS. We calculated the Multiple Sclerosis Severity Score (MSSS) using the EDSS. We mapped ICD codes into PheCodes (phenotypes), using a published system with each PheCode representing a unique medical condition. Association between the MSSS and the presence of each condition was assessed using logistic regression adjusted for covariates.

\section{Results}

The discovery and extension cohorts included 3,439 and 4,876 participants, respectively. After Bonferroni correction and covariate adjustments, a higher MSSS was associated with 37 coexisting conditions in the discovery cohort. Subsequently, 16 conditions, including genitourinary, infectious, metabolic, epilepsy, and movement disorders, met the reporting criteria, reaching the Bonferroni threshold of significance with the same direction of effect in the discovery and extension cohort. Notably, benign neoplasm of the skin was inversely associated with the MSSS.

\section{Conclusion}

The phenome-wide approach enabled a systematic interrogation of the comorbidity burden and highlighted clinically relevant medical conditions associated with MS severity (beyond MS-specific consequences) and defines a roadmap for comprehensive investigation of comorbidities in chronic neurologic diseases. Further prospective investigation of the bidirectional relationship between disability and comorbidities could inform the individualized patient management.

\author{
Correspondence \\ Dr. Xia \\ zxia1@pitt.edu
}




\section{Glossary}

BC $=$ British Columbia CLIMB $=$ Comprehensive Longitudinal Investigations in MS $;$ EDSS $=$ Expanded Disability Status Scale; EHR = electronic health record; ICD = International Classification of Diseases; MSSS = Multiple Sclerosis Severity Score; PheWAS = phenome-wide association study.

People with chronic neurologic diseases such as MS exhibit variable disease trajectories. People with MS often develop coexisting conditions. Prior efforts relying on candidate phenotype approaches have linked comorbidities to diagnostic delay, treatment delay, increased hospitalization, decreased quality of life, and increased mortality. ${ }^{1,2}$ Thus, comorbidities likely constitute an important facet of the individual variation in MS.

Phenome-wide association studies (PheWASs) were originally designed to interrogate the multiple phenotypes associated with a given genetic variant. ${ }^{3}$ A central contribution of the PheWAS approach is the creation of a clinically informative disease classification system that consolidates related International Classification of Diseases (ICD) codes for each medical condition into a unique phenotype code (PheCode). ${ }^{4}$ This approach enables a more comprehensive and organized examination of the comorbidity burden than candidate approaches.

We conducted a PheWAS to systematically interrogate the relationship between MS severity and comorbidity burden in this proof-of-concept study. We hypothesized that this novel application of the PheWAS approach to comprehensively assess comorbidities could offer insights into the association between disability and the occurrence of comorbidities and guide future prospective studies and individualized management strategies.

\section{Methods}

\section{Data sources}

Following a common protocol, we conducted independent analyses using data from 2 large MS cohorts (Partners HealthCare, Boston, United States; British Columbia [BC], Canada). We preassigned the Boston cohort as discovery and $\mathrm{BC}$ as extension for analyses.

The discovery cohort comprised patients with MS seen at the Partners MS Center (Boston) between 1993 and 2014, including patients enrolled in the Comprehensive Longitudinal Investigations in MS (CLIMB) study, a well-characterized clinic-based prospective study. ${ }^{5}$ We previously merged electronic health records (EHRs) and CLIMB research data for these patients. ${ }^{6}$ We obtained all available inpatient and outpatient ICD-9 codes from the Partners HealthCare EHRs.

The extension cohort comprised patients with MS registered at MS clinics in BC between 1991 and 2004, with follow-up until 2008. We accessed linked clinical and health administrative data. The British Columbia MS database captured clinical data. We determined residential status in BC using provincial health care plan registration dates and captured demographic information from the $\mathrm{BC}$ Registration and Premium Billing Files ${ }^{7}$ and all available ICD codes from the population-based physician and hospital data (the Medical Service Plan and Discharge Abstract Databases). ${ }^{8,9}$ ICD-10 codes were converted to ICD-9 codes. $^{10}$

\section{Standard protocol approvals, registrations, and patient consents}

The relevant Institutional Review Boards at Partners HealthCare and University of British Columbia approved the deidentified data usage for this study.

\section{Eligibility criteria}

We included all individuals aged $\geq 18$ years with a neurologistconfirmed MS diagnosis, ${ }^{11,12}$ and $\geq 1$ recorded ICD code other than MS, and $\geq 1$ recorded Expanded Disability Status Scale (EDSS) measure (assessed $>3$ months from a relapse and within 3-40 years after MS symptom onset) (figure 1).

\section{MS disease severity}

We extracted relevant clinical data, including date of symptom onset, relapsing or progressive onset, and disability (EDSS scores from clinic visits) for all patients. We calculated the Multiple Sclerosis Severity Score (MSSS) ${ }^{13}$ independently in each cohort, using the EDSS scores observed at each disease duration in the respective local cohort, and assigned a single score to each individual using the median of their 3 most recent MSSS measures, if available. The MSSS provides a percentile-based cross-sectional assessment of severity that accounts for disease duration. Ten percent of each cohort belonged to each severity decile at each disease duration. We included EDSS scores measured $>3$ months from a relapse date (to capture measures taken during periods of stability) and within 3-40 years after symptom onset because (1) the MSSS is unstable for disease durations $<3$ years, and (2) individuals with EDSS scores $>40$ years after symptom onset were rare and differential survival of older individuals may bias the analyses.

\section{Coexisting conditions}

We determined the occurrence of coexisting medical conditions in patients with MS. Using a published disease classification system that consolidates multiple related ICD-9 codes of each unique medical condition, ${ }^{14}$ we mapped each ICD-9 code to a single clinically informative medical condition represented by a unique phenotype code (PheCode). To reduce 
Figure 1 Eligibility criteria for the discovery and extension study cohorts

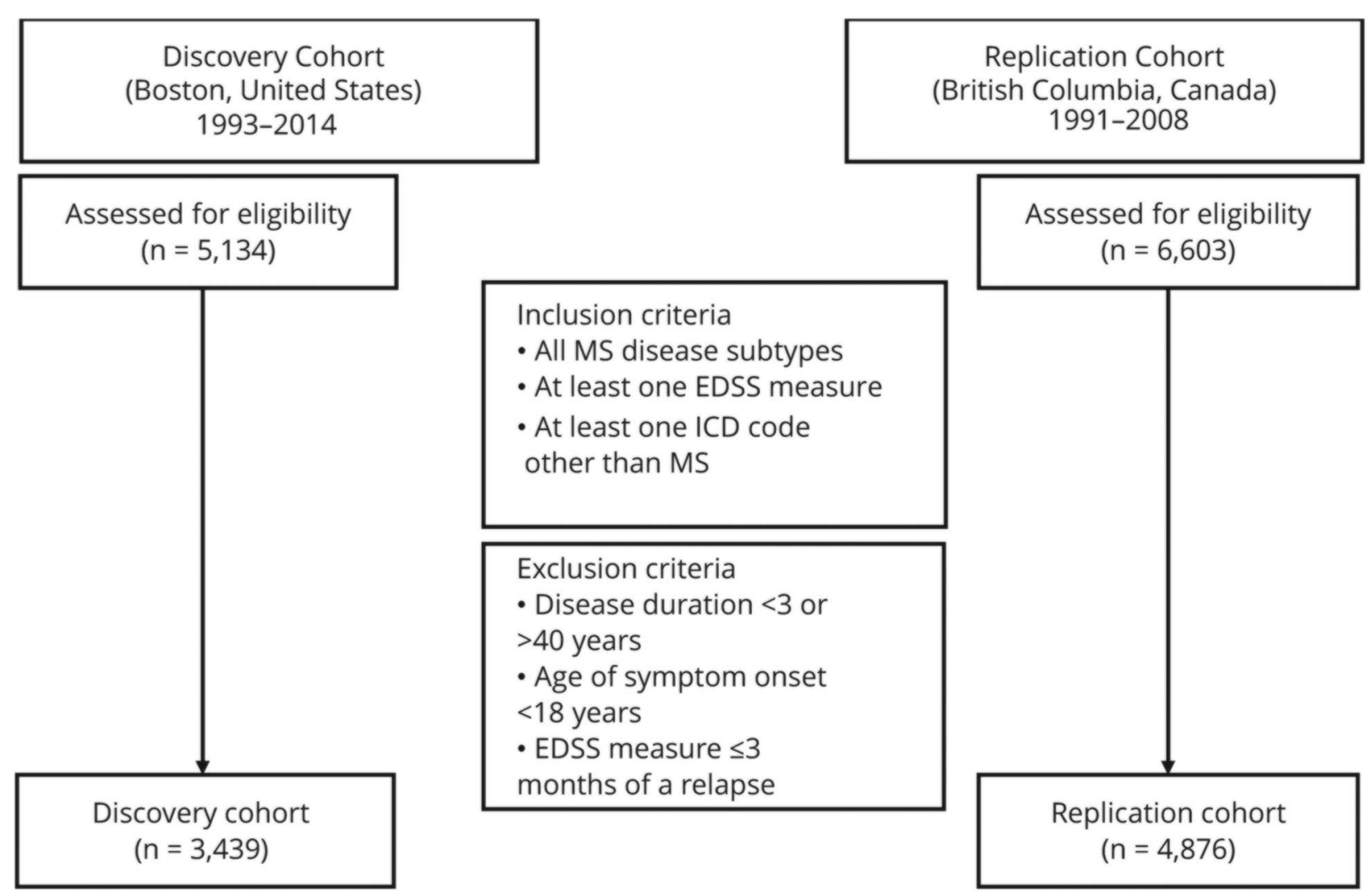

EDSS = Expanded Disability Status Scale; ICD = International Classification of Diseases.

the potential bias from rule-out codes (e.g., billing codes entered to indicate testing for, rather than confirming a medical condition), we excluded patients with $<3$ of a given ICD-9 code in the discovery analysis, ${ }^{15,16}$ whereas we assigned such patients to control status in the extension analysis due to complete capture of codified data in BC, made possible by its universal health care system. To mitigate double counting, multiple counts of a given ICD code on the same day and from the same clinic location were counted once.

\section{Statistical analysis}

In each cohort, we independently assessed associations between the MSSS and the presence (or absence) of each PheCode, with the MSSS modeled linearly as a continuous independent variable. The MSSS was modeled as a linear exposure because the alternative categorical division faced at least 2 challenges: the ideal threshold could differ for each comorbidity, and the effect on comorbidity could be nonmonotonic, neither increasing nor decreasing. We adjusted the model for confounders, including sex, age at symptom onset, disease course at symptom onset, ICD code follow-up duration (defined as the time from the first to the last available ICD code), and disease duration (defined as the time from MS symptom onset to the last available EDSS). We adjusted for disease duration to account for comorbidities that are predicted to occur with increasing disease duration. In the discovery analysis, we additionally adjusted for race and ethnicity (self-reported and grouped as non-Hispanic European ancestry, Hispanic or nonEuropean ancestry, and unknown), smoking status, and having a primary care provider who practices within the same hospital system as the EHR data. These additional covariates (race, ethnicity, smoking status, and presence of primary care provider) were not available in the extension cohort.

To reduce finite sample and rare event bias and prevent type I error, we excluded medical conditions for which the observed prevalence in each cohort was $<3 \%{ }^{17}$ In both cohorts, we defined the significance threshold as $p<0.05$ after Bonferroni correction. Our predefined reporting criteria for each finding required that (1) the association achieved the Bonferroni threshold of significance in both cohorts and (2) displayed the same direction of effect.

We used a previously published PheWAS table and R package to map ICD-9 codes into PheCodes. ${ }^{14}$ Analyses were performed using the Statistical Package for the Social Sciences (Version 20.0; IBM Corp., Armonk, NY) and R (Version 3.0.2). ${ }^{18}$

\section{Data availability}

Code for analysis and figure generation is available at tinyurl. $\mathrm{com} / \mathrm{y} 91 \mathrm{lu} 7 \mathrm{t} 3 \mathrm{t}$. Summary data that support the findings of this study as well as anonymous data from the Boston cohort that 
were used for this study are available on request to the corresponding author. The data from the $\mathrm{BC}$ cohort that were used for this study were accessed through Population Data BC (popdata.bc.ca/) and reside on a limited access secure research environment. For legal reasons (Canada), the data cannot leave this secure research environment.

\section{Results}

\section{Comparison of the study cohorts}

Patient characteristics of both cohorts were generally similar except that the extension cohort had a longer median followup duration from the first to the last EDSS value (table 1). In the discovery cohort, 3,439 patients with MS met the eligibility criteria for analysis (figure 1), whereas 109 medical conditions met the $3 \%$ prevalence threshold. In the extension cohort, 4,876 patients with MS met the eligibility criteria for analysis (figure 1), whereas 365 medical conditions met the $3 \%$ prevalence threshold. In total, 78 PheCodes or medical conditions met the $3 \%$ prevalence threshold in both cohorts.

The extension analysis (based on population-linked health administrative data in a universal health care system) systematically capture all available ICD codes, whereas the discovery analysis (based on EHRs in an open health care system) had fewer analyzable medical conditions that met the minimum case threshold. As such, we included the presence of primary care provider in the same EHR system as a key covariate in the discovery analysis. Furthermore, the longer follow-up duration in the extension cohort contributed to higher measured prevalence of medical conditions, which affected the observability of medical conditions that reached the threshold for inclusion in the analysis. Specifically, 287 PheCodes reached the $3 \%$ case threshold in the extension cohort but were excluded because they failed to reach the 3\% case threshold in the discovery cohort. For comparison, 31 PheCodes reached the $3 \%$ case threshold in the discovery cohort but were excluded due to failure to reach the $3 \%$ case threshold in the extension cohort (supplementary material, links.lww.com/NXI/A294).

\section{Comorbidities meeting the reporting criteria}

In the discovery cohort, a higher MSSS was significantly associated with 33 (of the 78, 42\%) coexisting medical conditions after Bonferroni correction and covariate adjustment. A total of 16 (of the 33, 48\%) conditions met the predefined criteria for reporting, having reached the Bonferroni threshold of significance (on 78 tests) and displaying a consistent direction of effect in both cohorts. Table 2 provides the prevalence of the coexisting conditions that met the reporting criteria as well as the effect size and $p$ values from the discovery and extension analysis.

Among the reported coexisting medical conditions associated with a higher MSSS, the 6 genitourinary conditions (other disorders of bladder [discovery: $\mathrm{OR}=1.45,95 \% \mathrm{CI}=$
$1.39-1.52, p=4.77 \times 10^{-58}$; extension: $\mathrm{OR}=1.25,95 \% \mathrm{CI}=$ $\left.1.22-1.28, p=1.82 \times 10^{-78}\right]$, functional disorders of bladder, other symptoms/disorders of the urinary system, hematuria, retention of urine, and urinary incontinence) had the strongest associations with MS severity as a category. These genitourinary conditions likely indicated MS-related morbidities, rather than comorbidities (table 2). Two coexisting infections likely result from MS immune-modifying treatments: pneumonia (discovery: $\mathrm{OR}=1.33,95 \% \mathrm{CI}=1.23-1.44, p=2.84 \times$ $10^{-12}$; extension: $\mathrm{OR}=1.16,95 \% \mathrm{CI}=1.14-1.19, p=1.04 \times$ $10^{-32}$ ) and fever of unknown origin (discovery: $\mathrm{OR}=1.23$, $95 \% \mathrm{CI}=1.16-1.30, p=2.18 \times 10^{-11}$; extension: $\mathrm{OR}=1.28$, $\left.95 \% \mathrm{CI}=1.22-1.35, p=1.89 \times 10^{-20}\right)$. Other infections are likely consequences of worsening physical and genitourinary function in more disabled patients: superficial cellulitis and abscess (discovery: $\mathrm{OR}=1.17,95 \% \mathrm{CI}=1.09-1.25, p=4.26 \times$ $10^{-6}$; extension: $\mathrm{OR}=1.07,95 \% \mathrm{CI}=1.05-1.09, p=5.33 \times$ $10^{-10}$ ) and urinary tract infection (discovery: $\mathrm{OR}=1.32,95 \%$ $\mathrm{CI}=1.26-1.38, p=7.41 \times 10^{-33}$; extension: $\mathrm{OR}=1.36,95 \%$ $\left.\mathrm{CI}=1.33-1.40, p=5.90 \times 10^{-11}\right)$.

Beyond the genitourinary and infectious conditions, other comorbidities meeting the predefined reporting criteria (table 2 ) included epilepsy (epilepsy, recurrent seizures, convulsions [discovery: $\mathrm{OR}=1.19,95 \% \mathrm{CI}=1.11-1.27, p=3.31 \times 10^{-7}$; extension: $\left.\mathrm{OR}=1.13,95 \% \mathrm{CI}=1.09-1.16, p=2.65 \times 10^{-14}\right]$, convulsions $[$ discovery: $\mathrm{OR}=1.21,95 \% \mathrm{CI}=1.12-1.30, p=$ $2.60 \times 10^{-7}$; extension: $\mathrm{OR}=1.23,95 \% \mathrm{CI}=1.17-1.30, p=$ $2.49 \times 10^{-15} \mathrm{~J}$ ), metabolic disturbance (disorders of fluid, electrolyte, and acid-base balance [discovery: $\mathrm{OR}=1.26,95 \%$ $\mathrm{CI}=1.16-1.36, p=1.08 \times 10^{-8}$; extension: $\mathrm{OR}=1.27,95 \%$ $\left.\left.\mathrm{CI}=1.22-1.32, p=1.41 \times 10^{-35}\right]\right)$, abnormal movement (discovery: $\mathrm{OR}=1.24,95 \% \mathrm{CI}=1.19-1.30, p=1.39 \times 10^{-19}$; extension: $\mathrm{OR}=1.11,95 \% \mathrm{CI}=1.08-1.14, p=9.97 \times 10^{-14}$ ), and gastrointestinal discomfort (nausea and vomiting [discovery: $\mathrm{OR}=1.21,95 \% \mathrm{CI}=1.12-1.30, p=1.36 \times 10^{-6}$; extension: $\left.\mathrm{OR}=1.07,95 \% \mathrm{CI}=1.04-1.12, p=1.73 \times 10^{-4}\right]$ ). Of interest, benign neoplasm of the skin was inversely associated with the MSSS in both cohorts (discovery: $\mathrm{OR}=0.89$, 95\% CI $=0.85-0.94, p=4.93 \times 10^{-6}$; extension: $\mathrm{OR}=0.92$, $\left.95 \% \mathrm{CI}=0.90-0.94, p=1.67 \times 10^{-14}\right)$. The observed correlations among the reported comorbidities suggest that the predetermined Bonferroni threshold of significance was likely conservative (figure 2), but it was important for the main findings to adhere to the predefined reporting criteria.

\section{Comorbidities not meeting the reporting criteria}

A number of conditions that did not meet the stringent predefined reporting criteria are noteworthy. First, we found different coexisting psychiatric conditions with greater MS severity in the 2 cohorts. Mood disorders such as depression $\left(\mathrm{OR}=1.17,95 \% \mathrm{CI}=1.12-1.22, p=2.83 \times 10^{-14}\right)$ and adjustment reaction $(\mathrm{OR}=1.15,95 \% \mathrm{CI}=1.10-1.20, p=1.86$ $\times 10^{-9}$ ) reached significance threshold only in the discovery analysis (table e-1, links.lww.com/NXI/A294), whereas schizophrenia $(\mathrm{OR}=1.12,95 \% \mathrm{CI}=1.07-1.16, p=9.94 \times$ 
Table 1 Characteristics of the MS cohorts

\begin{tabular}{|c|c|c|}
\hline Patient characteristics & $\begin{array}{l}\text { Discovery cohort (Boston, United } \\
\text { States) } N=3,439\end{array}$ & $\begin{array}{l}\text { Extension cohort (British Columbia, } \\
\text { Canada) } \mathrm{N}=4,876\end{array}$ \\
\hline Age at symptom onset, y, median (Q1-Q3) & $33.0(27.1-40.9)$ & $31.9(25.8-39.5)$ \\
\hline Female, $\mathbf{N}(\%)$ & $2,524(73)$ & $3,535(72)$ \\
\hline Non-Hispanic European, $\mathbf{N}(\%)$ & $2,947(86)$ & Not available \\
\hline $\begin{array}{l}\text { Disease duration (MS symptom onset to the last EDSS), y, } \\
\text { median (Q1-Q3) }\end{array}$ & $13.4(8.3-20.9)$ & $14.5(8.7-22.7)$ \\
\hline Unique ICD-9 code count, N, median (Q1-Q3) & $7(3-18)$ & $17(3-45)$ \\
\hline $\begin{array}{l}\text { Duration from the first to the last } I C D-9 \text { code, } y \text {, median } \\
\text { (Q1-Q3) }\end{array}$ & $11.3(6.5-15.4)$ & $12.9(6.0-15.5)$ \\
\hline $\begin{array}{l}\text { Duration from the first to the last EDSS value, } y \text {, median } \\
\text { (Q1-Q3) }\end{array}$ & $6.0(3.0-9.8)$ & $10.5(4.2-14.5)$ \\
\hline \multicolumn{3}{|l|}{ Disease course, $n$ (\%) } \\
\hline Progressive onset & $378(11)$ & $433(8.9)$ \\
\hline Relapsing onset & $3,061(89)$ & $4,443(91)$ \\
\hline
\end{tabular}

Abbreviations: EDSS = Expanded Disability Status Scale; $I C D=$ International Classification of Diseases.

$\left.10^{-8}\right)$ and psychosis $(\mathrm{OR}=1.14,95 \% \mathrm{CI}=1.08-1.19, p=1.69$ $\times 10^{-7}$ ) did so only in the extension analysis (table e-2). Second, although osteoporosis $(\mathrm{OR}=1.40,95 \% \mathrm{CI}=$ $\left.1.30-1.51, p=2.08 \times 10^{-19}\right)$ and osteoporosis, osteopenia, and pathologic fracture $(\mathrm{OR}=1.21,95 \% \mathrm{CI}=1.16-1.27, p=$ $1.47 \times 10^{-15}$ ) reached the significance threshold only in the discovery analysis (table e-1), related conditions such as several types of fractures (e.g., fracture of lower limb $[\mathrm{OR}=$ $\left.\left.1.11,95 \% \mathrm{CI}=1.07-1.15, p=2.70 \times 10^{-9}\right]\right)$ were also significant in the extension analysis (table e-2). Third, several notable vascular conditions did not meet the stringent predefined reporting criteria in our study (tables e- 1 and e-2). Diabetes (discovery: $\mathrm{OR}=1.17,95 \% \mathrm{CI}=1.08-1.25, p=4.20$ $\times 10^{-5}$ ), cerebrovascular (extension: $\mathrm{OR}=1.08,95 \% \mathrm{CI}=$ 1.04-1.11, $p=8.43 \times 10^{-6}$ ), and peripheral vascular disease (extension: $\mathrm{OR}=1.15,95 \% \mathrm{CI}=1.10-1.20, p=1.28 \times 10^{-8}$ ) reached significance in only 1 cohort. Hyperlipidemia did not reach significance in either cohort. Hypertension had opposite direction of effect (discovery: $\mathrm{OR}=1.09,95 \% \mathrm{CI}=$ $1.04-1.14, p=5.50 \times 10^{-4}$; extension: $\mathrm{OR}=0.93,95 \% \mathrm{CI}=$ $\left.0.91-0.95, p=5.52 \times 10^{-10}\right)$. Finally, some comorbidities expected in severe MS, such as physical impairment (e.g., other paralytic syndromes $[\mathrm{OR}=1.42,95 \% \mathrm{CI}=1.37-1.46, p$ $\left.=1.85 \times 10^{-10}\right]$ ) and chronic ulcers (e.g., decubitus ulcers $\left.\left[\mathrm{OR}=1.80,95 \% \mathrm{CI}=1.66-1.94, p=7.73 \times 10^{-49}\right]\right)$, reached significance only in the extension analysis but not in the discovery analysis (tables e- 1 and e-2).

\section{Independent discovery analysis}

Analyzing the discovery cohort data independently, we identified 42 (of the 109 that met the $3 \%$ prevalence threshold, 39\%) coexisting medical conditions that were significantly associated with a higher MSSS after Bonferroni correction and covariate adjustment (table e-1, links.lww. com/NXI/A294, figures 3A and 4A). Of the 31 PheCodes that reached the $3 \%$ case threshold in the discovery cohort data (but were excluded from the discovery analysis due to failure to reach the $3 \%$ case threshold in the extension cohort), 9 medical conditions are significantly associated with the MSSS after Bonferroni adjustment in an independent analysis of discovery data. Of these 9 conditions, 2 had prevalence above $10 \%$ in the discovery cohort.

\section{Independent extension analysis}

Analyzing the extension cohort data independently, we identified 130 (of the 365 that met the 3\% prevalence threshold, 36\%) coexisting medical conditions that were significantly associated with a higher MSSS after Bonferroni correction and covariate adjustment (table e-2, links.lww. com/NXI/A294, figures 3B and 4B). Of the 287 PheCodes that reached the $3 \%$ case threshold in the extension cohort (but were excluded from the extension analysis due to failure to reach the $3 \%$ case threshold in the discovery cohort), we found that 90 of these medical conditions are significantly associated with the MSSS after Bonferroni adjustment in the independent analysis of the $\mathrm{BC}$ extension cohort data. Of these 90 medical conditions, 39 had prevalence above $10 \%$ in the extension cohort.

\section{Discussion}

In this study of 2 large independent cohorts, we deployed a phenome-wide approach to comprehensively assess the comorbidity burden associated with higher disease severity in MS. Notwithstanding the differences between the 2 cohorts 
Table 2 Coexisting medical conditions associated higher MS severity scores

\begin{tabular}{|c|c|c|c|c|c|c|c|c|c|c|c|}
\hline \multirow{3}{*}{$\begin{array}{l}\text { PheCode }^{a} \\
216\end{array}$} & \multirow{3}{*}{$\begin{array}{l}\text { Reported medical condition }^{\mathbf{b}, \mathbf{c}} \\
\text { Benign neoplasm of skin }\end{array}$} & \multicolumn{5}{|c|}{ Discovery } & \multicolumn{5}{|c|}{ Extension } \\
\hline & & \multirow{2}{*}{$\begin{array}{l}\text { Prev }^{\text {d }} \\
(\%)\end{array}$} & \multirow{2}{*}{\begin{tabular}{|l}
$\mathbf{O R}^{\mathbf{e}}$ \\
0.89
\end{tabular}} & \multicolumn{2}{|c|}{ OR $95 \% \mathrm{Cl}$} & \multirow{2}{*}{$\begin{array}{l}p \text { Value } \\
4.93 \mathrm{E}-06\end{array}$} & \multirow{2}{*}{$\begin{array}{l}\text { Prev } \\
\text { (\%) }\end{array}$} & \multirow{2}{*}{$\begin{array}{l}\text { OR } \\
0.92\end{array}$} & \multicolumn{2}{|c|}{ OR $95 \% \mathrm{Cl}$} & \multirow{2}{*}{$\begin{array}{c}p \text { Value } \\
1.67 \mathrm{E}-14\end{array}$} \\
\hline & & & & 0.85 & 0.94 & & & & 0.90 & 0.94 & \\
\hline 276 & $\begin{array}{l}\text { Disorders of fluid, electrolyte, and acid-base } \\
\text { balance }\end{array}$ & 3.8 & 1.26 & 1.16 & 1.36 & $1.08 \mathrm{E}-08$ & 8.9 & 1.27 & 1.22 & 1.32 & $1.41 \mathrm{E}-35$ \\
\hline 345 & Epilepsy, recurrent seizures, convulsions & 4.0 & 1.19 & 1.11 & 1.27 & $3.31 \mathrm{E}-07$ & 11.4 & 1.13 & 1.09 & 1.16 & $2.65 \mathrm{E}-14$ \\
\hline 345.3 & Convulsions & 3.3 & 1.21 & 1.12 & 1.30 & $2.60 \mathrm{E}-07$ & 4.0 & 1.23 & 1.17 & 1.30 & $2.49 \mathrm{E}-15$ \\
\hline 350 & Abnormal movement & 10.8 & 1.24 & 1.19 & 1.30 & $1.39 \mathrm{E}-19$ & 14.9 & 1.11 & 1.08 & 1.14 & $9.97 \mathrm{E}-14$ \\
\hline 480 & Pneumonia & 3.6 & 1.33 & 1.23 & 1.44 & $2.84 \mathrm{E}-12$ & 21.0 & 1.16 & 1.14 & 1.19 & $1.04 \mathrm{E}-32$ \\
\hline 591 & Urinary tract infection & 14.5 & 1.32 & 1.26 & 1.38 & $7.41 \mathrm{E}-33$ & 25.8 & 1.36 & 1.33 & 1.40 & $5.90 \mathrm{E}-11$ \\
\hline 593 & Hematuria & 5.4 & 1.29 & 1.21 & 1.38 & $5.48 \mathrm{E}-15$ & 5.3 & 1.12 & 1.07 & 1.17 & $1.11 \mathrm{E}-06$ \\
\hline 596 & Other disorders of bladder & 15.9 & 1.45 & 1.39 & 1.52 & 4.77E-58 & 30.9 & 1.25 & 1.22 & 1.28 & $1.82 \mathrm{E}-78$ \\
\hline 596.5 & Functional disorders of bladder & 15.6 & 1.44 & 1.38 & 1.51 & $1.40 \mathrm{E}-56$ & 15.6 & 1.31 & 1.27 & 1.35 & $6.16 \mathrm{E}-69$ \\
\hline 599 & $\begin{array}{l}\text { Other symptoms/disorders of the urinary } \\
\text { system }\end{array}$ & 18.8 & 1.33 & 1.28 & 1.38 & $1.81 \mathrm{E}-42$ & 59.5 & 1.13 & 1.11 & 1.15 & $6.57 \mathrm{E}-30$ \\
\hline 599.2 & Retention of urine & 4.0 & 1.35 & 1.25 & 1.45 & $5.28 \mathrm{E}-14$ & 6.8 & 1.32 & 1.26 & 1.38 & $7.61 \mathrm{E}-33$ \\
\hline 599.4 & Urinary incontinence & 7.9 & 1.40 & 1.32 & 1.48 & $3.83 E-28$ & 9.3 & 1.16 & 1.12 & 1.20 & $3.89 \mathrm{E}-17$ \\
\hline 681 & Superficial cellulitis and abscess & 4.9 & 1.17 & 1.09 & 1.25 & $4.26 \mathrm{E}-06$ & 36.8 & 1.07 & 1.05 & 1.09 & $5.33 \mathrm{E}-10$ \\
\hline 783 & Fever of unknown origin & 6.1 & 1.23 & 1.16 & 1.30 & $2.18 \mathrm{E}-11$ & 4.4 & 1.28 & 1.22 & 1.35 & $1.89 \mathrm{E}-20$ \\
\hline 789 & Nausea and vomiting & 3.3 & 1.21 & 1.12 & 1.30 & $1.36 \mathrm{E}-06$ & 7.2 & 1.07 & 1.04 & 1.12 & $1.73 \mathrm{E}-04$ \\
\hline \multicolumn{12}{|c|}{$\begin{array}{l}\text { a Related International Classification of Diseases, Ninth Revision, codes of a single medical condition are mapped to a single phenotype code or PheCode } \\
\text { (column 1). } \\
\text { b Predefined reporting criteria are meeting the Bonferroni threshold of statistical significance and having the same direction of effect in both the discovery } \\
\text { cohort and the extension cohort. } \\
\text { c Description of the PheCode or the medical condition (column } 2 \text { ) is directly extracted from a publicly available mapping tool without further editing by the } \\
\text { authors. }{ }^{14} \\
\text { d Prevalence (Prev) is defined as the percentage of the patients in the cohort having a medical condition as indicated by the PheCode. }\end{array}$} \\
\hline
\end{tabular}

(health care systems, billing practices, and data integration), we reported 16 coexisting medical conditions that met the predefined stringent reporting criteria for reaching the Bonferroni threshold of significance and displaying the same direction of effect in both cohorts. Our application of the PheWAS approach sets the road map for comprehensive comorbidity investigation in other chronic neurological diseases.

Consistent with prior targeted approaches investigating predetermined candidate conditions, ${ }^{19}$ we found an overrepresentation of genitourinary conditions among the reported comorbidities associated with MS severity, after accounting for conditions that are predicted to occur with increasing disease duration. It is important to note that some of the reported coexisting conditions, particularly the genitourinary disorders, are known MS-related morbidities rather than independent comorbidities. Importantly, the disproportionally large number of genitourinary conditions that met the stringent reporting criteria not only confirms the clinical experience of the large impact of disease severity on the genitourinary system in MS but also reaffirms the validity of the PheWAS approach in highlighting this category of conditions.

Another comorbidity category associated with a higher MSSS was infectious diseases, including urinary tract infection, pneumonia, superficial cellulitis and abscess, and fever of unknown origin (likely secondary to an underlying infection). Prior studies reported higher prevalence of infections among MS than the general population, ${ }^{20,21}$ attributable to older age or the use of disease-modifying therapies. ${ }^{22}$ Infections such as abscess and cellulitis can also result from physical debilitation. Infections contribute to MS mortality ${ }^{23}$ and increase MS relapse risk. ${ }^{24}$ Furthermore, relapses associated with an infection might result in greater neurologic damage (relative to relapses without comorbid infections) and greater long-term severity. ${ }^{25}$ Our study again highlights infections associated with MS severity, independent of age, while reaffirming the PheWAS approach. 
Figure 2 Correlation structure of the reported coexisting medical conditions (as indicated by PheCodes) associated with higher MS severity scores

A

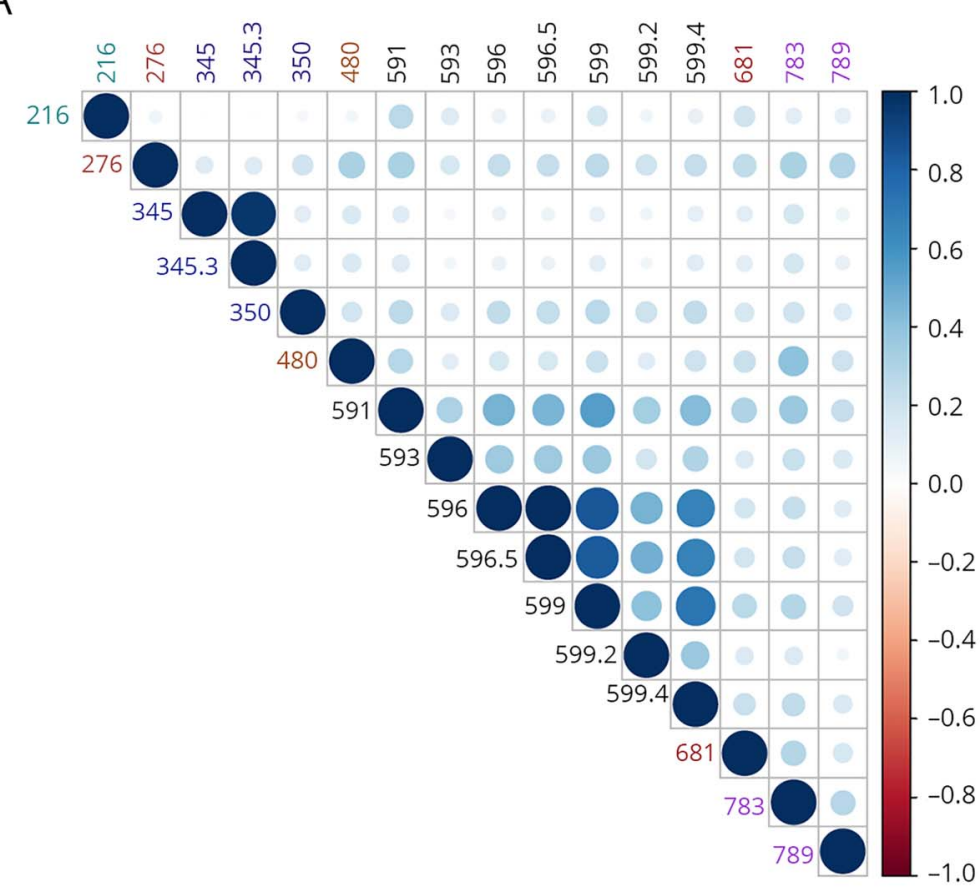

B
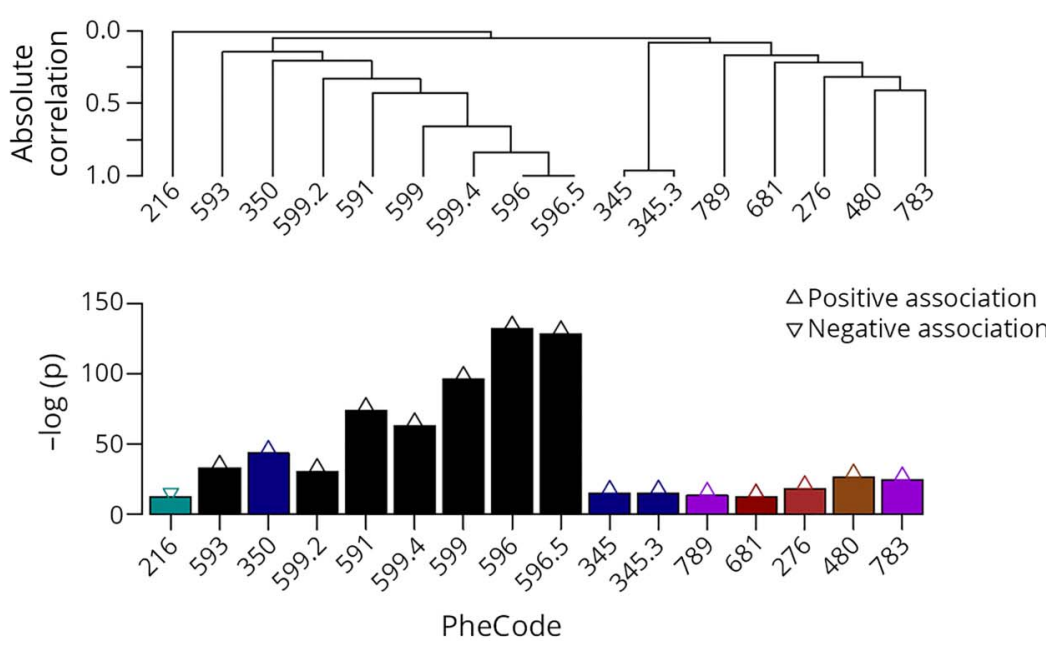

As shown in a heat map (A) and in a hierarchical clustering (B) format. The color saturation and the circle size in the heatmap both indicate the strength of (positive or negative) correlation between 2 medical conditions. Reporting criteria were defined as meeting the Bonferroni threshold of statistical significance and having the same direction of effect in both the discovery cohort and the extension cohort. Strength of association $-\log (p$ value) from the extension cohort is shown. Refer to table 2 for explanation of each phenotype code (PheCode).

Among the reported findings, epilepsy and disorders of fluid, electrolyte, and acid-base balance are underappreciated for their association with MS severity, though consistent with anecdotal clinical observation. Building on the known prevalence of epilepsy among MS (2\%), ${ }^{26}$ our finding of epilepsy in association with MS severity is consistent with a prior study $^{27}$ and may be due to irritation from MS lesions. Disorders of fluid, electrolyte, and acid-base as a category of comorbid metabolic disturbance also commonly occur in patients with heart diseases or renal failure and may also reflect poor diet, fluid intake, or swallowing difficulties in severe MS. ${ }^{28}$ Indeed, another reported finding is nausea and vomiting, which could contribute to metabolic disturbance. Finally, abnormal movement was a reported finding that warrants targeted investigation, particularly given report of increased frequency of movement disorder even early in $\mathrm{MS}^{29}$

Although we set out to investigate the comorbidity burden associated with MS severity, we found an interesting inverse association between MS severity and certain cancers, including benign neoplasm of the skin. Prior studies reported a lower incidence of all-cause cancers among people with MS relative to matched general population. ${ }^{30,31}$ Diagnostic neglect, particularly in those with more severe disability, could be contributory. ${ }^{30}$ As an alternative explanation, less sun exposure and lower serum vitamin $\mathrm{D}$ level early in the disease 
Figure 3 Manhattan plots of the mapped coexisting medical conditions associated with higher MS severity scores
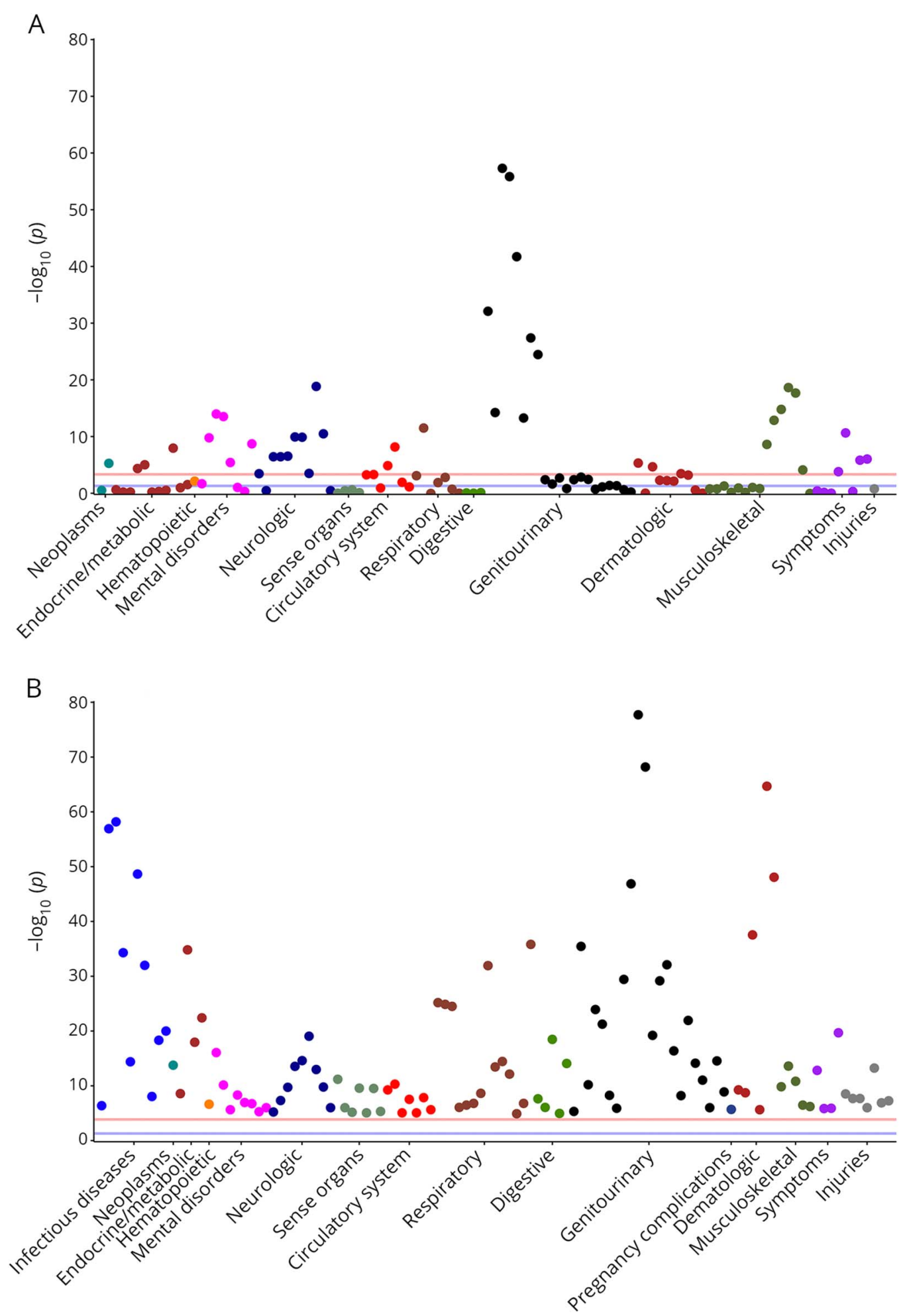

PheCode

Conditions that met the requirement of minimum cases and respective - $\log (p$ values): findings from independent analysis in the discovery cohort (A) and extension cohort (B). Refer to table e-1 and table e-2 (links.Iww.com/NXI/A294) for details of each condition. The red line indicates the threshold of significance after Bonferroni correction and covariate adjustment; the blue line represents $p=0.05$. 
Figure 4 Plot of estimated OR and cohort prevalence for mapped coexisting medical conditions associated with higher MS severity scores (MSSS)
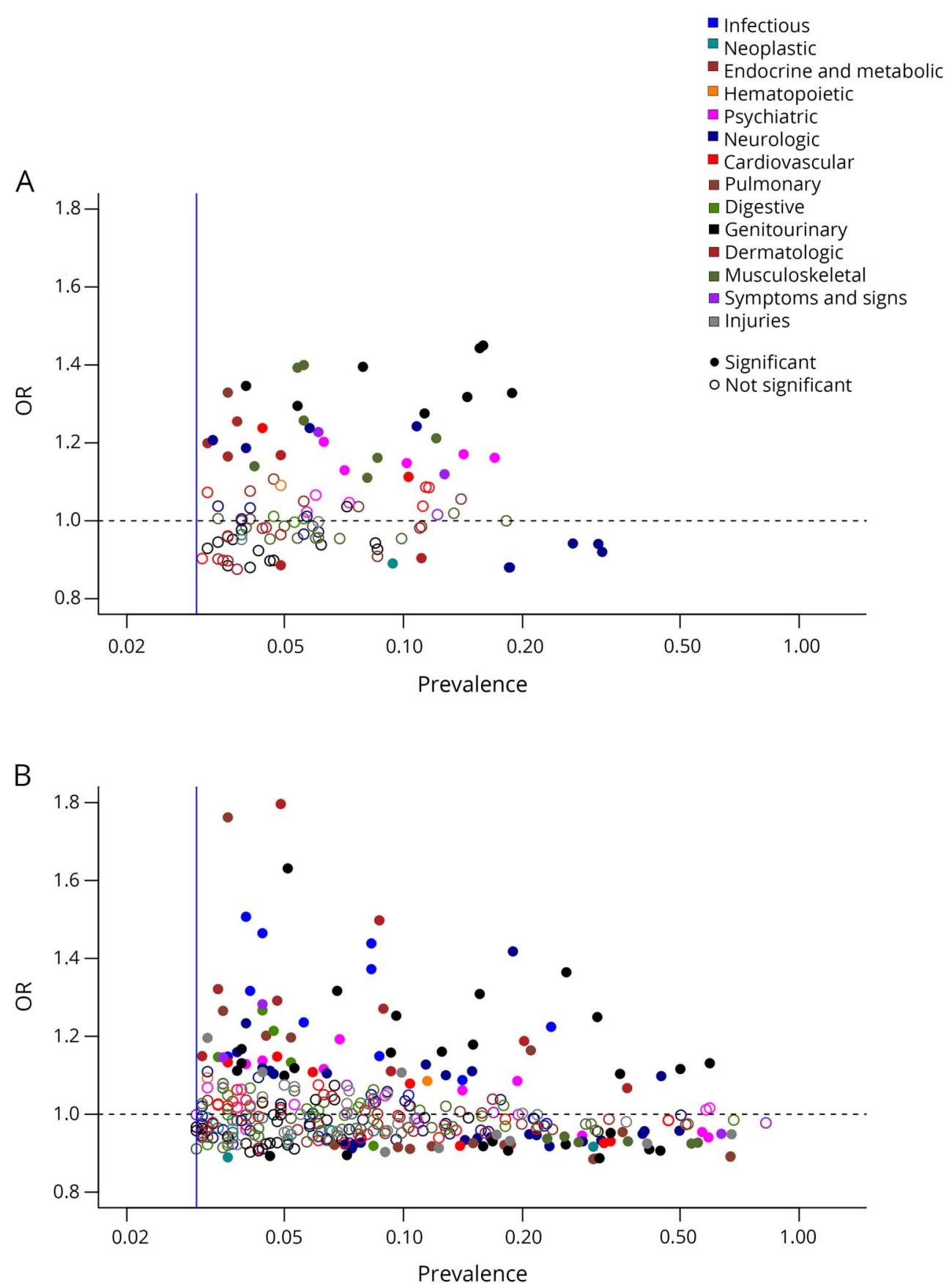

Findings from independent analysis in the discovery cohort $(A)$ and extension cohort (B). Results below the dotted lines are inverse associations. ORs represent per unit increase of the MSSS (on the decile scale).

course may contribute to greater MS relapse risk and greater disease worsening in some patients with MS. ${ }^{32}$

We made several other interesting observations with respect to the comorbidity burden in MS. First, we found comorbid psychiatric conditions with MS severity in the 2 cohorts, although the relationships are inconsistent. Of interest, a prior study reported that the presence of psychiatric conditions increased the severity of subsequent neurologic disability. ${ }^{33} \mathrm{We}$ could not rule out the possibility that (1) population differences in the prevalence and management of mental health conditions within each cohort contributed to these differences, (2) validation could be achieved with less stringent criteria, or (3) disease severity as measured by the MSSS may not consistently correlate with psychiatric comorbidities. Second, osteoporosis reached the significance threshold in the discovery analysis only, whereas related conditions (e.g., several types of fractures) were significant in the extension analysis. Together, these findings suggest a higher risk of osteoporosis and related complications in those with a greater MS severity, which may 
be associated with vitamin $\mathrm{D}$ deficiency early in the disease and reduced mobility in more disabled individuals and is consistent with the report of higher prevalence of osteoporosis in MS than controls. ${ }^{34}$ Third, several notable vascular conditions such as cerebrovascular and peripheral vascular disease, diabetes, hyperlipidemia, and hypertension did not meet the stringent predefined reporting criteria in our study. Vascular diseases were previously reported to be associated with MS severity. ${ }^{35-38}$ Finally, some comorbidities expected in severe MS, such as physical impairment (e.g., hemiplegia and paralytic syndromes) and chronic ulcers (e.g., decubitus ulcers), were found only in the extension analysis but not in the discovery analysis. Some of the inconsistencies with prior reports could reflect differences in the study design, study population, and the method with which comorbidities were identified, whereas differences in reaching the stringent reporting criteria between the 2 cohorts could be attributable to differences in billing practices between the 2 distinct health care systems, the greater ability to systematically capture all ICD codes in the extension cohort (Canada) than the discovery cohort (United States), and longer follow-up duration in the extension cohort than the discovery cohort. Although the application of stringent reporting criteria is a strength of our study, those medical conditions identified only in a single cohort warrant further investigation.

Our study had several limitations. First, the ICD system captures a broad spectrum of diagnoses, but studies based on $I C D$ data inevitably encounter potential incompleteness and misclassification. We took steps to mitigate these issues by systematically capturing all available ICD codes, consolidating ICD codes related to a single medical condition, and establishing minimum case requirement for each medical condition. Second, a related limitation pertinent to the discovery cohort was that not all patients had primary care providers in the same health care system as the source EHRs data. Primary care providers are more likely to record all available ICD codes in the EHRs than subspecialty physicians. In a multipayer health care system such as the United States, incomplete capture of ICD codes is more common for patients whose primary care providers are not in the same hospital system because the EHRs of one hospital system may not capture codes for care received at outside facilities. To mitigate this issue in the discovery analysis, we included the presence of primary care providers within the same hospital system as the EHRs data as a covariate. Despite these differences between the 2 cohorts and the use of stringent reporting criteria, our study found 16 coexisting comorbidities, which point to the robustness of the PheWAS approach. Finally, our crosssectional association study does not draw causal conclusions, and the PheWAS approach may not sufficiently distinguish the direction of effect or the direct consequence between MS severity and comorbidities. Indeed, we calculated the MSSS to obtain a stable cross-sectional measure of severity based on up to the 3 most recent EDSS scores and associated disease durations. If we were to require the EDSS to precede (or follow) the occurrence of an ICD code, there would be insufficient number of events (ICD-9 codes) to permit adequately powered analyses, and the analyses may have mismeasurement of the timing of the first occurrence of an ICD-9 code due to incomplete records. Our present study paves the way for future prospective investigations, which will be critical to establish temporal relationships between disability assessment and coexisting condition occurrence and account for all potentially important confounders.

In summary, our novel application of the phenome-wide approach systematically identified the comorbidity burden and informed clinically relevant and lesser appreciated comorbidities associated with disease severity in a chronic neurologic disease, MS. Future prospective investigation of the comorbidity burden in relation to worsening disability may help realize individualized monitoring and management of patients with severe MS.

\section{Acknowledgment}

The authors thank Mariann Polgar-Turcsanyi, Andrew Cagan, and Vivian Gainer for providing technical assistance for the Boston cohort data extraction. They gratefully acknowledge the British Columbia MS Clinic neurologists who contributed to the study through patient examination and data collection (current members at the time of data extraction listed here by primary clinic). UBC MS Clinic: A. Traboulsee, MD, FRCPC (UBC Hospital MS Clinic Director and Head of the UBC MS Programs); A-L. Sayao, MD, FRCPC; V. Devonshire, MD, FRCPC; S. Hashimoto, MD, FRCPC (UBC and Victoria MS Clinics); J. Hooge, MD, FRCPC (UBC and Prince George MS Clinic); L. Kastrukoff, MD, FRCPC (UBC and Prince George MS Clinic); J. Oger, MD, FRCPC. Kelowna MS Clinic: D. Adams, MD, FRCPC; D. Craig, MD, FRCPC; S. Meckling, MD, FRCPC. Prince George MS Clinic: L. Daly, MD, FRCPC Victoria MS Clinic: O. Hrebicek, MD, FRCPC; D. Parton, MD, FRCPC; KAtwell-Pope, MD, FRCPC. The authors gratefully acknowledge Partners MS Clinic neurologists who contributed to the study through patient examination and data collection. The views expressed in this article do not necessarily reflect the views of each individual acknowledged. The British Columbia Ministry of Health approved access to and use of data from British Columbia, Canada, facilitated by Population Data British Columbia. All inferences, opinions, and conclusions drawn in this study are those of the authors and do not reflect the opinions or policies of the Data Stewards.

\section{Study funding}

T. Zhang, M. Goodman, F. Zhu, R. Carruthers, T. Chitnis, H. Weiner, and T. Cai report no disclosures relevant to the manuscript. B. Healy has received research funding from Merck Serono S.A., Verily Life Sciences, Genzyme, and Novartis and has served on an advisory board for Biogen Idec (none relevant to this study). P. De Jager was a Harry Weaver Neuroscience Scholar of the National Multiple Sclerosis Society (JF2138A1) and has research funding from Biogen and Sanofi/Genzyme (none relevant to this study). H. Tremlett is the Canada Research Chair for Neuroepidemiology and Multiple Sclerosis. Current research support received from the National Multiple Sclerosis Society, the 
Canadian Institutes of Health Research, the Multiple Sclerosis Society of Canada, and the Multiple Sclerosis Scientific Research Foundation. In addition, in the last 5 years, has received research support from the UK MS Trust and travel expenses to present at CME conferences from the Consortium of MS Centres (2018), the National MS Society (2016 and 2018), ECTRIMS/ ACTRIMS (2015, 2016, 2017, 2018, and 2019), and American Academy of Neurology (2015, 2016, and 2019). Speaker honoraria are either declined or donated to an MS charity or to an unrestricted grant for use by HT's research group. Z. Xia was a recipient of the Clinician Scientist Development Award from the National Multiple Sclerosis Society and the American Academy of Neurology and is supported by NIH R01-NS098023.

\section{Disclosure}

None relevant to the study. Go to Neurology.org/NN for full disclosures.

\section{Publication history}

Received by Neurology: Neuroimmunology \& Neuroinflammation March 2, 2020. Accepted in final form June 17, 2020.

\section{Appendix Authors}

\begin{tabular}{lll}
\hline Name & Location & Contribution \\
\hline $\begin{array}{l}\text { Tingting } \\
\text { Zhang, PhD }\end{array}$ & Brown University & $\begin{array}{l}\text { Designed and conceptualized } \\
\text { the study; analyzed the data; } \\
\text { and drafted and revised the } \\
\text { manuscript for intellectual } \\
\text { content }\end{array}$ \\
\end{tabular}

\begin{tabular}{ll}
\hline Matthew & Harvard T.H.Chan \\
Goodman, & School of Public \\
PhD & Health
\end{tabular}

Designed and conceptualized the study; analyzed the data; and drafted and revised the manuscript for intellectual content

\begin{tabular}{lll}
\hline $\begin{array}{l}\text { Feng Zhu, } \\
\text { MSc }\end{array}$ & $\begin{array}{l}\text { University of } \\
\text { British Columbia }\end{array}$ & $\begin{array}{l}\text { Major role in the acquisition of } \\
\text { the data and analyzed the data }\end{array}$ \\
\hline $\begin{array}{l}\text { Brian Healy, } \\
\text { PhD }\end{array}$ & $\begin{array}{l}\text { Brigham and } \\
\text { Women's Hospital }\end{array}$ & $\begin{array}{l}\text { Major role in the acquisition of } \\
\text { the data; interpreted data; and } \\
\text { revised the manuscript for } \\
\text { intellectual content }\end{array}$
\end{tabular}

\begin{tabular}{lll}
\hline $\begin{array}{l}\text { Robert } \\
\text { Carruthers, } \\
\text { MD }\end{array}$ & $\begin{array}{l}\text { University of } \\
\text { British Columbia }\end{array}$ & $\begin{array}{l}\text { Major role in the acquisition of } \\
\text { the data }\end{array}$ \\
\hline $\begin{array}{l}\text { Tanuja } \\
\text { Chitnis, MD }\end{array}$ & $\begin{array}{l}\text { Brigham and } \\
\text { Women's Hospital }\end{array}$ & $\begin{array}{l}\text { Major role in the acquisition of } \\
\text { the data and revised the } \\
\text { manuscript for intellectual } \\
\text { content }\end{array}$
\end{tabular}

\begin{tabular}{lll}
\hline $\begin{array}{l}\text { Howard } \\
\text { Weiner, MD }\end{array}$ & $\begin{array}{l}\text { Brigham and } \\
\text { Women's Hospital }\end{array}$ & $\begin{array}{l}\text { Major role in the acquisition of } \\
\text { the data }\end{array}$ \\
\hline $\begin{array}{l}\text { Tianxi Cai, } \\
\text { ScD }\end{array}$ & $\begin{array}{l}\text { Harvard T.H. Chan } \\
\text { School of Public } \\
\text { Health }\end{array}$ & $\begin{array}{l}\text { Interpreted data and revised the } \\
\text { manuscript for intellectual } \\
\text { content }\end{array}$ \\
\hline $\begin{array}{l}\text { Philip De } \\
\text { Jager, MD, } \\
\text { PhD }\end{array}$ & $\begin{array}{l}\text { Columbia } \\
\text { University }\end{array}$ & $\begin{array}{l}\text { Designed and conceptualized } \\
\text { the study; major role in the } \\
\text { acquisition of the data; } \\
\text { interpreted data; and revised } \\
\text { the manuscript for intellectual } \\
\text { content }\end{array}$ \\
\hline
\end{tabular}

Appendix (continued)

\begin{tabular}{lll}
\hline Name & Location & Contribution \\
\hline $\begin{array}{l}\text { Helen } \\
\text { Tremlett, } \\
\text { PhD }\end{array}$ & $\begin{array}{l}\text { University of } \\
\text { British Columbia }\end{array}$ & $\begin{array}{l}\text { Designed and conceptualized the } \\
\text { study; major role in the } \\
\text { acquisition of the data; } \\
\text { interpreted data; and revised the } \\
\text { manuscript for intellectual } \\
\text { content }\end{array}$ \\
\hline $\begin{array}{l}\text { Zongqi Xia, } \\
\text { MD, PhD }\end{array}$ & University of & $\begin{array}{l}\text { Designed and conceptualized the } \\
\text { study; major role in the } \\
\text { acquisition of the data; analyzed } \\
\text { data; interpreted data; and } \\
\text { drafted and revised the } \\
\text { manuscript for intellectual } \\
\text { content }\end{array}$ \\
& &
\end{tabular}

T. Zhang, M. Goodman, H. Tremlett, and Z. Xia had full access to all the data in the study and take responsibility for the integrity of the data, the accuracy of the data analysis, and the decision to submit for publication. All authors have seen and approved the submitted version of the manuscript.

\section{References}

1. Marrie RA. Comorbidity in multiple sclerosis: implications for patient care. Nat Rev Neurol 2017;13:375-382. doi: 10.1038/nrneurol.2017.33.

2. Tettey P, Siejka D, Simpson S, et al. Frequency of comorbidities and their association with clinical disability and relapse in multiple sclerosis. Neuroepidemiology 2016;46: 106-113. doi: 10.1159/000442203.

3. Denny JC, Bastarache L, Roden DM. Phenome-wide association studies as a tool to advance precision medicine. Annu Rev Genom Hum Genet 2016;17:353-373. doi: 10.1146/annurev-genom-090314-024956.

4. Denny JC, Ritchie MD, Basford MA, et al. PheWAS: demonstrating the feasibility of a phenome-wide scan to discover gene-disease associations. Bioinformatics 2010;26: 1205-1210. doi: 10.1093/bioinformatics/btq126.

5. Gauthier SA, Glanz BI, Mandel M, Weiner HL. A model for the comprehensive investigation of a chronic autoimmune disease: the multiple sclerosis CLIMB study. Autoimmun Rev 2006;5:532-536. doi: 10.1016/j.autrev.2006.02.012.

6. Xia Z, Secor E, Chibnik LB, et al. Modeling disease severity in multiple sclerosis using electronic health records. PLoS One 2013;8:e78927. doi: 10.1371/journal.pone. 0078927.

7. BC Ministry of Health [creator]. Consolidation File (MSP Registration \& Premium Billing). BC Ministry of Health; 2011. Data Extract. MOH (2009). Available at: www2.gov.bc.ca/gov/content/health/conducting-health-research- evaluation/dataaccess-health-data-central. Accessed June 8, 2020.

8. Canadian Institute of Health Information [creator]. Discharge Abstract Database (Hospital Separations). British Columbia Ministry of Health; 2011. Data Extract. MOH (2011). Available at: www2.gov.bc.ca/gov/content/health/conductinghealth- research-evaluation/data-access-health-data-central. Accessed June 8, 2020.

9. BC Ministry of Health [creator]. Medical Services Plan (MSP) Payment Information File. Population Data BC. 2011. Data Extract. MOH (2010). Available at: www2.gov. bc.ca/gov/content/health/conducting-health-research-evaluation/data-accesshealth-data-central. Accessed June 8, 2020.

10. Canadian Institute for Health Information (CIHI). Canadian Coding Standards for Version 2018 ICD-10-CA and CCI. Available at: https://secure.cihi.ca/free_products/CodingStandards_v2018_EN.pdf. Accessed August 5, 2020.

11. Poser CM, Paty DW, Scheinberg L, et al. New diagnostic criteria for multiple sclerosis: guidelines for research protocols. Ann Neurol 1983;13:227-231. doi: 10.1002/ana. 410130302.

12. McDonald WI, Compston A, Edan G, et al. Recommended diagnostic criteria for multiple sclerosis: guidelines from the International Panel on the diagnosis of multiple sclerosis. Ann Neurol 2001;50:121-127. doi: 10.1002/ana.1032.

13. Roxburgh RHSR, Seaman SR, Masterman T, et al. Multiple Sclerosis Severity Score: using disability and disease duration to rate disease severity. Neurology 2005;64: 1144-1151. doi: 10.1212/01.WNL.0000156155.19270.F8.

14. Carroll RJ, Bastarache L, Denny JC. R PheWAS: data analysis and plotting tools for phenome-wide association studies in the R environment. Bioinformatics 2014;30: 2375-2376. doi: 10.1093/bioinformatics/btu197.

15. Denny JC, Bastarache L, Ritchie MD, et al. Systematic comparison of phenome-wide association study of electronic medical record data and genome-wide association study data. Nat Biotechnol 2013;31:1102-1110. doi: 10.1038/nbt.2749.

16. Hebbring SJ, Schrodi SJ, Ye Z, Zhou Z, Page D, Brilliant MH. A PheWAS approach in studying HLA-DRB1*1501. Genes Immun 2013;14:187-191. doi: 10.1038/gene. 2013.2.

17. Liao KP, Sparks JA, Hejblum BP, et al. Phenome-wide association study of autoantibodies to citrullinated and noncitrullinated epitopes in rheumatoid arthritis. Arthritis Rheumatol 2017;69:742-749. doi: 10.1002/art.39974. 
18. R Core Team. R: A Language and Environment for Statistical Computing. 2016. Available at: R-project.org/. Accesse April 1, 2020.

19. Ineichen BV, Schneider MP, Hlavica M, Hagenbuch N, Linnebank M, Kessler TM. High EDSS can predict risk for upper urinary tract damage in patients with multiple sclerosis. Mult Scler J 2017;24:529-534. doi: 10.1177/1352458517703801.

20. Wijnands JM, Kingwell E, Zhu F, et al. Infection-related health care utilization among people with and without multiple sclerosis. Mult Scler J 2016;65:1352458516681198. doi: $10.1177 / 1352458516681198$.

21. Montgomery S, Hillert J, Bahmanyar S. Hospital admission due to infections in multiple sclerosis patients. Eur J Neurol 2013;20:1153-1160. doi: 10.1111/ene. 12130.

22. Wijnands JMA, Zhu F, Kingwell E, et al. Disease-modifying drugs for multiple sclerosis and infection risk: a cohort study. J Neurol Neurosurg Psychiatry 2018;89: 1050-1056. doi: 10.1136/jnnp-2017-317493.

23. Manouchehrinia A, Tanasescu R, Tench CR, Constantinescu CS. Mortality in multiple sclerosis: meta-analysis of standardised mortality ratios. J Neurol Neurosurg Psychiatry 2016;87:324-331. doi: 10.1136/jnnp-2015-310361.

24. Buljevac D, Flach HZ, Hop WCJ, et al. Prospective study on the relationship between infections and multiple sclerosis exacerbations. Brain 2002;125:952-960.

25. Perry VH, Newman TA, Cunningham C. The impact of systemic infection on the progression of neurodegenerative disease. Nat Rev Neurosci 2003;4:103-112. doi: 10. 1038/nrn1032.

26. Catenoix H, Marignier R, Ritleng C, et al. Multiple sclerosis and epileptic seizures. Mult Scler J 2011;17:96-102. doi: 10.1177/1352458510382246.

27. Zhang $\mathrm{T}$, Tremlett $\mathrm{H}$, Zhu $\mathrm{F}$, et al. Effects of physical comorbidities on disability progression in multiple sclerosis. Neurology 2018;90:e419-e427. doi: 10.1212/WNL. 0000000000004885 .

28. Guan X-L, Wang H, Huang H-S, Meng L. Prevalence of dysphagia in multiple sclerosis: a systematic review and meta-analysis. Neurol Sci 2015;36:671-681. doi: 10 . 1007/s10072-015-2067-7.
29. Abboud H, Yu XX, Knusel K, Fernandez HH, Cohen JA. Movement disorders in early MS and related diseases: a prospective observational study. Neurol Clin Pract 2019;9: 24-31. doi: 10.1212/CPJ.0000000000000560.

30. Kingwell E, Bajdik C, Phillips N, et al. Cancer risk in multiple sclerosis: findings from British Columbia, Canada. Brain 2012;135:2973-2979. doi: 10.1093/brain/ aws 148 .

31. Thormann A, Koch-Henriksen N, Laursen B, Sørensen PS, Magyari M. Inverse comorbidity in multiple sclerosis: findings in a complete nationwide cohort. Mult Scler Relat Disord 2016;10:181-186. doi: 10.1016/j.msard.2016.10.008.

32. Simpson S, van der Mei I, Lucas RM, et al. Sun exposure across the life course significantly modulates early multiple sclerosis clinical course. Front Neurol 2018;9: 16. doi: $10.3389 /$ fneur.2018.00016.

33. McKay KA, Tremlett H, Fisk JD, et al. Psychiatric comorbidity is associated with disability progression in multiple sclerosis. Neurology 2018;90:e1316-e1323. doi: 10. 1212/WNL.0000000000005302.

34. Bisson EJ, Finlayson ML, Ekuma O, Leslie WD, Marrie RA. Multiple sclerosis is associated with low bone mineral density and osteoporosis. Neurol Clin Pract 2019;9: 391-399. doi: 10.1212/CPJ.0000000000000669.

35. Roshanisefat H, Bahmanyar S, Hillert J, Olsson T, Montgomery S. Multiple sclerosis clinical course and cardiovascular disease risk-Swedish cohort study. Eur J Neurol 2014;21:1353-e88. doi: 10.1111/ene.12518.

36. Marrie RA, Rudick R, Horwitz R, et al. Vascular comorbidity is associated with more rapid disability progression in multiple sclerosis. Neurology 2010;74:1041-1047. doi: 10.1212/WNL.0b013e3181d6b125.

37. Tettey P, Simpson S, Taylor BV, van der Mei IAF. Vascular comorbidities in the onset and progression of multiple sclerosis. J Neurol Sci 2014;347:23-33. doi: 10.1016/j. jns.2014.10.020.

38. Kowalec K, McKay KA, Patten SB, et al. Comorbidity increases the risk of relapse in multiple sclerosis: a prospective study. Neurology 2017;89:2455-2461. doi: 10.1212/ WNL.0000000000004716. 


\title{
Neurology \\ Neuroimmunology \& Neuroinflammation
}

\author{
Phenome-wide examination of comorbidity burden and multiple sclerosis disease \\ severity \\ Tingting Zhang, Matthew Goodman, Feng Zhu, et al. \\ Neurol Neuroimmunol Neuroinflamm 2020;7; \\ DOI 10.1212/NXI.0000000000000864
}

This information is current as of August 19, 2020

Updated Information \&

Services

References

Citations

Subspecialty Collections

Permissions \& Licensing

Reprints including high resolution figures, can be found at:

http://nn.neurology.org/content/7/6/e864.full.html

This article cites 33 articles, 4 of which you can access for free at: http://nn.neurology.org/content/7/6/e864.full.html\#\#ref-list-1

This article has been cited by 1 HighWire-hosted articles: http://nn.neurology.org/content/7/6/e864.full.html\#\#otherarticles

This article, along with others on similar topics, appears in the following collection(s):

Electronic medical records

http://nn.neurology.org//cgi/collection/electronic_medical_records Multiple sclerosis

http://nn.neurology.org//cgi/collection/multiple_sclerosis

Information about reproducing this article in parts (figures,tables) or in its entirety can be found online at:

http://nn.neurology.org/misc/about.xhtml\#permissions

Information about ordering reprints can be found online:

http://nn.neurology.org/misc/addir.xhtml\#reprintsus

Neurol Neuroimmunol Neuroinflamm is an official journal of the American Academy of Neurology.

Published since April 2014, it is an open-access, online-only, continuous publication journal. Copyright

Copyright (C) 2020 The Author(s). Published by Wolters Kluwer Health, Inc. on behalf of the American

Academy of Neurology.. All rights reserved. Online ISSN: 2332-7812.

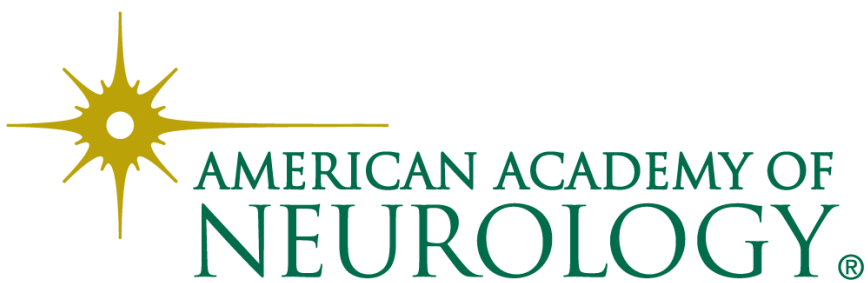

